Revista Destaques Acadêmicos, Lajeado, v. 10, n. 1, 2018. ISSN 2176-3070

DOI: http://dx.doi.org/10.22410/issn.2176-3070.v10i1a2018.1774

http://www.univates.br/revistas

\title{
DEMONSTRAÇÃO DO PERTENCIMENTO DO POVO GAÚCHO ATRAVÉS DO CONSUMO DE MODA CONTEMPORÂNEA
}

\author{
Raquel Hauschild ${ }^{1}$
}

\begin{abstract}
Resumo: Este estudo tem como objetivo compreender o papel da moda contemporânea no processo de demonstração de sentimento de pertencimento do povo gaúcho. Para esse fim, foi conduzida uma pesquisa de natureza exploratória e qualitativa, por meio de entrevistas em profundidade junto a vinte e um consumidores que apresentavam algum tipo de envolvimento ou capacidade de reflexão crítica em relação à cultura gaúcha, ao uso e percepção da moda contemporânea como uma forma de expressão. A análise dos resultados apontou que os entrevistados em sua maioria entendem que ao vestir uma roupa contemporânea com referências à cultura gaúcha, estarão demonstrando o seu sentimento de pertencimento. Porém, as pessoas ligadas ao Movimento Tradicionalista Gaúcho entendem que esta é uma forma de desrespeitar a cultura tradicional gaúcha, resistindo, mesmo que parcialmente, à ideia de associar uma moda mais contemporânea à tradição gaúcha. Assim, conclui-se que a moda contemporânea é uma forma emergente de expressão do pertencimento à cultura gaúcha por parte de consumidores que não demonstram apego ao tradicionalismo, mas buscam igualmente manifestar o seu pertencimento local.
\end{abstract}

Palavras-chave: Cultura gaúcha. Identidade cultural. Hibridismo cultural. Moda contemporânea. Pertencimento. Tradicionalismo.

\section{INTRODUÇÃO}

Com o processo de globalização e tecnologias tais como a internet foi possível aproximar cada vez mais as pessoas que estão distantes fisicamente. Devido a estes novos contatos gerados e facilitados na pós-modernidade, num mundo líquido (BAUMAN, 2001) e efêmero (LIPOVETSKY, 2009), o processo de construção de identidades pode ser alterado (HALL, 2006), reduzindo o papel da cultura local no processo de construção de identidades. Porém, para Canclini (2007), ao mesmo tempo em que as identidades passam a ser

1 Bacharel em Administração de Empresas, da Universidade do Vale do Taquari - UNIVATES, Lajeado/RS. hauschild@universo.univates.br; keel.hauschild@gmail.com 
construídas globalmente, as pessoas mantêm um desejo de preservação de vínculos locais, que está ligado ao sentimento de pertencimento. Assim, surge uma situação dicotômica, na qual, ao mesmo tempo em que as identidades locais são substituídas por vínculos globais, as pessoas buscam encontrar formas de pertencimento a algo.

Neste sentido, a moda aparece como um elemento importante. A moda está ligada ao vestuário e a objetos que compõem as vestimentas das pessoas (SVENDSEN, 2010, apud OLIVEIRA, 2013). Porém, ela pode ir muito além disso, tornando-se uma forma de expressão, uma demonstração do sentimento de pertencimento a uma cultura ou local. A compreensão desse fenômeno passa pela identificação de contextos localizados, nos quais o pertencimento à determinada cultura pode ser manifestado pela moda. Um destes contextos é a cultura gaúcha. Fruto de uma hibridação de culturas, ela utiliza-se significativamente da moda para expressar e demostrar a sua tradição e os seus hábitos locais (OLIVEN, 1993). Reflexo disso é o estabelecimento de regras e normas pelo Movimento Tradicionalista Gaúcho (MTG) capazes inclusive de indicar qual a forma correta de um peão e uma prenda se vestirem de acordo com a cultura tradicionalista gaúcha.

Baseado neste contexto, o objetivo do presente trabalho é compreender o papel da moda contemporânea no processo de demonstração de sentimento de pertencimento do povo gaúcho. Para isso, é válido destacar a importância do estudo da cultura global de consumo e também dos gaúchos, que foi sofrendo alterações ao decorrer dos anos, devido aos impactos da globalização, sendo que estas mutações acontecem em todos os lugares, inclusive no Rio Grande do Sul. Para isso, os capítulos seguintes fazem uso da lente teórica do marketing e dos estudos de consumo visando revelar a complexidade das relações sociais e culturais (que existem em todos os lugares) que permeiam a moda e o pertencimento local.

\section{REFERENCIAL TEÓRICO}

\subsection{Identidade cultural e a globalização}

Para Woodward (2000, p. 9) a identidade é "marcada pela diferença": entre as pessoas, entre a cultura delas, entre as atitudes, costumes e dentre tantas outras coisas, visto que sempre seremos uns diferentes dos outros. A identidade também é manifestada através de símbolos e objetos simbólicos que representam um pouco da cultura do indivíduo.

Sobre o conceito de "identidade cultural", Hall (2003) indica que existem duas formas diferentes de se representar o conceito em questão. A primeira está relacionada à busca de uma comunidade para recuperar a "verdade" sobre a sua história, o seu passado, a sua cultura. Já a segunda forma está relacionada ao que se vê como cultura, ao que se pode visualizar, isto não significa que 
fatos históricos não tenham sentido ou valor, pois é isso que faz as pessoas desejarem resgatar coisas que tinham antes, sem esquecer que o passado passa por modificações.

Douglas (2004) apresenta a ideia de que diferença é a base da cultura, e isso acontece por meio de sistemas simbólicos que representam algo. Woodward (2000) afirma que a cultura proporciona meios pelos quais é possível dar sentido ao mundo em que vivemos e assim construir e designar os sentidos, as coisas. A cultura também influencia na concepção do indivíduo moderno, como será apresentado no próximo subcapítulo.

Costa (2002) indica que a globalização influencia nas identidades e nos locais onde elas estão inseridas. Comenta sobre o processo de homogeneização que está se desenvolvendo em relação às culturas de massas ou de atomização individualista generalizada. Afirma que é possível fazer uma conexão entre o processo de globalização com a identidade, homogeneização e o hibridismo cultural (CANCLINI, 2007). Canclini (1997) reforça que devido ao processo de globalização, que aproximou mais as coisas e as pessoas através de novos meios de comunicação, é possível dizer que as sociedades vêm se tornando homogeneizadas, recebendo então o nome de "culturas", pois agora não é mais tão fácil e perceptível diferenciar e separar uma cultura da outra como antes, quando eram consideradas heterogêneas. Com isso, as culturas se aproximam, se misturam (multiculturalismo), gerando assim também o hibridismo cultural.

Esse processo não é diferente na cultura gaúcha. Gobbi (2007) ressalta que a cultura gaúcha é resultado da mistura, da fusão de diversas outras culturas que vieram de todos os cantos do mundo e aqui se estabeleceram pelos mais diversos motivos. Para a autora essa mistura, junção, união de culturas em um mesmo local, representa o "enriquecimento de signos e significações permeado pelos meios de comunicação de massa, é tradução de uma história específica, um ritmo próprio, com peculiaridades mostradas nos tempos históricos e subjetivos" (GOBBI, 2007, p. 21).

Pesavento (1993) faz sua análise em relação aos gaúchos afirmando que a sociedade apesar de ter elementos que teriam sido inventados, acaba acreditando em seus mitos e ainda acrescenta símbolos, e assim reconhece a sua identidade como ela é dita. Destaca que a representação idealizada que é transmitida pode ser uma estratégia consciente ou não, para assim se fazer pertencer a um mundo de reconhecimento e de respeito pelo o que se é. Assim, a cultura gaúcha é tomada como um recurso na construção identitária, capaz de promover um sentimento de pertencimento a algo num mundo complexo e globalizado. Em específico, destaca-se o papel da moda na demonstração do pertencimento do povo gaúcho. 


\subsection{Moda fashion}

Moda, segundo Svendsen (2010 apud OLIVEIRA, 2013), é um conceito difícil de ser definido, pois é bem amplo, mas de forma geral, está relacionado com o vestuário, objetos que compõem as vestimentas das pessoas, com base em diferentes referências, possuindo assim uma atribuição maior do que apenas nos vestir. Lipovetsky (2009) afirma que é um meio pelo qual ocorrem mudanças sociais, sendo indiferente qual o objeto que está ligado à moda. Estas mutações são ligadas à efemeridade do ambiente em que a moda está inserida, permitindo assim também atingir diversos níveis e pontos da sociedade. "A moda produz objetos e símbolos, cria objetos portadores de significados, caracterizados pela criatividade e estética por meio da cultura, o que pode ser reconhecido nos grupos sociais ou manifestações culturalistas" (GODART, 2010 apud OLIVEIRA, 2013, p. 14). Ou seja, a moda é uma forma de expressão de culturas e características das identidades dos indivíduos, sendo assim, são geradas inúmeras manifestações culturais por todos.

A moda vai além de apenas vestir-se, escolher uma peça de roupa na loja e utilizá-la. Segundo Lipovetsky (2009), muitas vezes escolhemos de forma inconsciente, mas sempre é algo que representa um pouco de como somos, uma pouco de nossa identidade. E também devido aos novos conceitos de estilo de vida apresentados nos tempos atuais, onde a moda é uma forma de expressão e representa as "características individuais e comportamentais dos indivíduos com a realidade de vida de cada um" (COBRA, 2007, p. 11).

Como a pesquisa está relacionada com a cultura do Rio Grande do Sul, apresenta-se uma relação mais específica quanto à conexão entre a moda e as culturas regionais. Conforme Lipovetsky (2009), as roupas e as formas com que são utilizadas tornam-se em objetos que privilegiam a compreensão de práticas relacionadas às representações sociais. Estas formas relacionam-se entre si e com outras diversas práticas das sociedades, ajudando a compor a cultura do local.

No Rio Grande do Sul existem algumas tradições bem particulares ligadas à cultura e tradições locais. Existem por exemplo, as roupas femininas e masculinas que são ditas como vestimentas tradicionais gaúchas. Os trajes que caracterizam o gaúcho são um dos símbolos do Estado, inclusive havendo a sua regulamentação por meio da Lei Estadual $n^{\circ}$ 8.813, de 10 de Janeiro de 1989, que determina que a indumentária receberia a nomenclatura de "pilcha gaúcha" e que somente seria considerada adequada com base no que fosse determinado pelo Movimento Tradicionalista Gaúcho (MTG).

O MTG (2014) possui várias regras bem específicas que classificam as peças de roupas como sendo ou não uma "pilcha gaúcha", que possa ser utilizada para atividades artísticas ou sociais, sendo que existem regras diferentes para as vestimentas femininas e masculinas. 
Conforme Desbessell (1999) as regras para as vestimentas típicas gaúchas já foram muito mais criteriosas, porém para não criar maiores restrições e acabar por afastar as pessoas do movimento, se abriu mão de algumas coisas. Com o passar do tempo, a moda começou a influenciar os gostos e a forma de consumir das pessoas, e este também foi um dos motivos pelos quais aconteceram mudanças nas normas, para assim, ficar um pouco mais flexível, atraindo mais pessoas para o grupo, desta forma, auxiliando a levar a tradição para mais e mais pessoas. Os elementos tais como vestimentas e acessórios tradicionalistas, fazem referência à cultura da população do Estado do Rio Grande do Sul, compondo assim as características da moda gaúcha.

\subsection{Consumo e cultura}

O consumo para Arnould e Thompson (2005) não é um sistema unificado, pelo qual se estuda apenas um fato, mas sim, todo um contexto cultural que influencia nos hábitos de consumo dos consumidores de todo o mundo, principalmente após o início da globalização. Para entender este fenômeno são realizados estudos, para descobrir mais sobre a complexidade cultural. $\mathrm{O}$ ato de consumir, de comprar, não se relaciona com a função específica do bem/ serviço adquirido, e sim pelo o que isso representa dentro do contexto pessoal, mas principalmente no social (SOLOMON, 2011).

Assim, Canclini (2006) entende que através do consumo de bens materiais e simbólicos é que o indivíduo realiza a sua integração, interação e se diferencia na sociedade. É também por meio do consumo que os indivíduos se tornam cidadãos. Douglas e Isherwood (2004) também desenvolvem a ideia de que o consumo passa a estar ligado não apenas ao fato de comprar, de gastar dinheiro, mas podendo ser para pertencer a um grupo, também como uma forma de identificação e ao mesmo tempo diferenciação, onde as pessoas não são melhores nem piores do que as outras, apenas diferentes. Quando alguém pertence a um determinado grupo/cultura, utiliza-se de objetos simbólicos para demonstração da sua participação e integração a esta comunidade. Sendo assim, o consumo de itens relacionados à cultura em questão é estimulado, mesmo que de forma indireta. Ou seja, o meio em que se está irá determinar e estimular ou não; e a forma com que acontecerá o consumo, e não apenas o fator renda, como geralmente é avaliado por outros autores (DOUGLAS; ISHERWOOD, 2004).

A questão do consumo também se relaciona com o sentimento de pertencimento que as pessoas têm, sendo este cada vez mais frequente nas sociedades pós-modernas, considerado por Canclini (2007) como um efeito da globalização e da hibridação cultural. As pessoas acabam distanciandose do que as vincula e as referencia a um determinado local, à sua cultura. $\mathrm{O}$ sentimento de pertencimento e ou recuperação dele, pode ser manifestado através de algum objeto; e a moda é um meio para isso, estimulando-se assim o consumo. A pesquisa em questão está relacionada com os objetos simbólicos 
que são utilizados na moda contemporânea para demonstração do sentimento de pertencimento do povo gaúcho.

\section{PROCEDIMENTOS METODOLÓGICOS}

Andrade (2003) afirma que as pesquisas podem ser classificadas de várias formas, utilizando diferentes critérios que variam de acordo com o enfoque da pesquisa. A mesma autora ainda diz que, para oferecer noções introdutórias é suficiente delimitar as pesquisas quanto à de natureza, aos objetivos, aos procedimentos e ao objeto. Sendo assim, o estudo é de levantamento de dados, de natureza exploratória e qualitativa.

O estudo apresenta uma pesquisa exploratória, pois visa compreender em profundidade um fenômeno (VERGARA, 2000). Os sujeitos da pesquisa foram consumidores gaúchos com capacidade de contribuir com o estudo. Por se tratar de uma pesquisa exploratória-qualitativa, o estudo não está preocupado com a representatividade amostral dos respondentes em relação à população em questão, mas sim em obter informações em profundidade sobre as ações e forma de pensar de um grupo de indivíduos, neste caso, o povo gaúcho.

Ao todo, foram conduzidas vinte e uma entrevistas. A definição da quantidade a ser aplicada dependeu da saturação dos dados, ou seja, quando se entende que novas entrevistas não estão mais agregando novas informações à pesquisa, foi finalizada a coleta de dados. Este processo foi realizado durante o mês de março de 2017. Foi realizado através de entrevistas em profundidade com vinte e uma pessoas, seguindo basicamente o roteiro de entrevista, sendo que todas elas foram gravadas e posteriormente transcritas. As entrevistas foram feitas de forma presencial ou por meio da internet, utilizando o programa Skype, com vídeo-chamadas, obtendo como resultado mais de doze horas de gravações e cento e noventa e nove páginas de dados transcritos.

Depois da realização das entrevistas em profundidade e da transcrição destas, deu-se início ao processo de categorização das informações. Utilizou-se das teorias apresentadas por Bardin (2006) e Creswell (2007) no que se refere à parte inicial da análise dos dados gerados. Primeiramente todas as entrevistas foram analisadas, extraindo-se sentidos e criando-se contextos relacionados a tudo o que foi dito. Assim foram criadas categorias emergentes (pois foram criadas após a análise dos dados) que deram suporte para a construção do capítulo de análise dos resultados. 


\section{ANÁLISE DOS RESULTADOS}

\subsection{Moda e cultura gaúcha}

Os entrevistados foram questionados sobre o que eles entendiam por moda e se esta poderia ser utilizada como forma de expressão dos indivíduos. Muitas e diferentes foram as respostas. A seguir são apresentadas as mais interessantes e agregadoras ao trabalho. Luciane afirma que "A moda é muito momentânea, é bem difícil definir".

A entrevistada Shana tem uma definição também atual e que corrobora com a teoria de Bergamo (1998) de que moda é arte, sendo utilizada como forma de expressão também artística. Segue abaixo a fala de Shana.

Então, eu acho que moda é arte, sempre foi. Acho que a moda também é uma forma de a gente representar a história. A moda tem relação com questões econômicas, questões históricas, questões de comportamento, de relacionamento, então a moda tem em si muita coisa. Por exemplo, se a gente analisar a história da indumentária do RS, daí vai-se achar que lá por 1800, se usava um determinado tipo de roupa, porque o tecido que se tinha disponível era aquele, porque o trabalho no campo fazia com que se precisasse que a roupa fosse aquela, então, tudo isso está relacionado com a moda, a moda é uma forma de expressão de um tempo, de um sentimento, de uma personalidade. O humor da gente tem relação com a moda, acho que a moda é de fato uma forma de expressão.

Tiago discorre sobre o conceito de moda e acrescenta a ideia dos demais afirmando que a moda está em constante adaptação. O Jéferson comenta que para ele "a moda são as roupas no tempo". E que cada cultura, etnia, utiliza roupas diferentes e expressa sua cultura com vestimentas diferentes. E complementa "[...] eu acho que cada peça de roupa, por mais simples que ela seja, ela tem seus traços e suas importâncias".

Bruna apresenta a sua explicação em relação ao conceito moda.

Moda vai muito além do vestir. Mas o que eu entendo de moda é bastante coisa, afinal, sou formada em Design de Moda. A palavra moda em si, vai desde o teu jeito de falar... tem uma frase de um grande escritor da Moda, ele diz que a moda é global, mas a cultura é local. Então não adianta a moda ser camiseta de neon, se em determinada cultura, por exemplo, aqui no nosso vale do Taquari estamos no inverno, e isso não tem nada a ver com a nossa cultura, com os nossos gostos. A moda vai muito além do nome, do que a roupa. Tem relação com a cultura.

O que foi apresentado por Bruna e Shana vem ao encontro à questão da relação entre moda e as culturas. Bem como Jéferson, que afirmou que a 
moda são as roupas no tempo, ou seja, estas fazem parte da história de todas as culturas. As vestimentas são uma forma de expressão.

Considerando que a moda faz parte da história de qualquer cultura (LIPOVETSKY, 2004), com a cultura gaúcha não seria diferente, sofreu adaptações com relações históricas durante os anos, conforme indicou a professora de moda Cláudia.

O manual do MTG sobre as pilchas do gaúcho indica sobre a forma correta de mulheres e homens vestirem-se para poder participar das ações tradicionalistas. Alguns entrevistados comentaram que não se admite alguém no CTG que não esteja vestido conforme as regras, para eles esta é uma forma de preservação da cultura, entendem que sempre devem se pilchar da forma correta, conforme determinado pelas regras do Movimento. Modismos conforme comentado por eles não acrescentam à cultura, pois não estão corretos conforme o manual.

Ana e Bruna comentaram sobre as mudanças que aconteceram nos trajes típicos ao decorrer dos anos, de pequenos detalhes, como tipo de tecidos e babados, rendas. Cita também que são mudanças importantes e necessárias para a manutenção da cultura. Indicaram também a questão do uso das bombachas pelas mulheres, o que há algum tempo não seria aceitável. A peça foi adaptada ao corpo feminino, ficando mais justa, sendo utilizada no dia-adia, na lida do campo ou eventos campeiros.

\subsubsection{Moda contemporânea na cultura gaúcha e o comércio}

A moda contemporânea, que é referida no trabalho, são roupas, acessórios (joias, chapéus, lenços, dentre tantas outras peças) e calçados. Estes itens são comuns nos guarda-roupas das pessoas. Porém as peças que são citadas neste trabalho são por exemplo, camisas ou camisetas normais, mas que demonstrem algum detalhe que remeta à cultura gaúcha, tais como: desenho de algum cavalo ou então uma estampa étnica que relembre alguma região do Estado.

Durante a realização das entrevistas foi possível perceber mais comentários relativos à vestimenta feminina. Até porque esta historicamente foi sempre mais restrita do que os trajes típicos masculinos, pois as mulheres, de acordo com o tradicionalismo, poderiam apenas utilizar vestidos, calças estavam fora de cogitação.

O trabalho baseou-se em pessoas mais conhecidas do público como referência. Dentre elas estão Juliana e Shana, sendo que ambas são cantoras nativistas e participaram do processo de entrevista. A outra pessoa que foi indicada por Juliana foi a apresentadora de TV Valéria, porém com ela não foi possível a realização da entrevista. Estas se destacam pelo trabalho realizado e também pelos seus envolvimentos com a modernização da moda gaúcha. Em virtude das suas profissões, estas três pessoas utilizam roupas ditas normais, 
mas que apresentam traços e alusão à cultura gaúcha, assim referenciado também através de suas roupas o seu sentimento de pertencimento à cultura gaúcha.

Shana relatou um pouco sobre a sua história e o que passou devido à mudança na sua forma de vestir-se durante as suas apresentações artísticas. Comentou sobre o preconceito que sofreu em simplesmente escolher uma roupa diferente para fazer a sua demonstração de arte e de pertencimento à cultura gaúcha. Destacou que é importante preservar a cultura através dos meios indicados pelo MTG, porém entende que possui liberdade de expressão tanto na arte dela, da personalidade dela, e em relação ao seu pertencimento à cultura.

Outra cantora nativista entrevistada foi a Juliana, que também passou por situações diferentes e traz com ela concepções opostas a dos tradicionalistas em relação a estas novas modas de vestir-se com referências à cultura. Ela afirma que adora usar peças como camisetas e blusas com estampas de cavalos, usa com muita frequência, é algo que já faz parte do seu dia a dia. Juliana reforça isso afirmando que precisa associar a imagem dela de cantora nativista também com elementos do meio, mas não necessariamente com a pilcha, diz que gosta muito desta nova moda.

É importante destacar que estas novas modas com referências às roupas tradicionais gaúchas, tornam-se mais usuais para o cotidiano. Como disse Shana, era uma necessidade que as pessoas sentiam, até que alguém resolveu investir e arriscar neste mercado. E foi isso que a empresária Gerti fez, ela é proprietária da primeira loja de vestimentas tradicionais no RS que começou a mudança, deu o start à fabricação e comercialização destas roupas mais modernas.

A entrevistada Gerti teve seu nome citado pela entrevistada Juliana, que comentou sobre a ousadia da empresária em decidir no ano de 2010 a mudar o mercado de vestimentas gaúchas, que deixou de ser apenas tradicionalista e abriu espaço para um novo nicho de mercado, para a moda contemporânea, mais moderna, com referências na cultura gaúcha. Para Gerti, Shana tem razão quando afirma que as pessoas já desejavam esta mudança, mas ninguém oferecia estes produtos.

Segue um trecho da entrevista em que a empresária define qual o público-alvo da sua marca, qual o nicho de mercado que hoje está sendo atendido com essa nova proposta de moda.

O nosso público não são as pessoas que estão lá dentro do CTG, nem aquelas que vivem em rodeios, são os outros tantos habitantes do nosso RS. Aqueles gaúchos que são gaúchos por causa da localização, da tradição do estado, da cultura do estado, mas que não vivem no seu dia a dia isso. E a gente pensou: vamos vestir estas outras pessoas que adoram, que se usam deste pertencimento. É para aquelas pessoas que adoram, que amam serem 
gaúchos, mas que não frequentam o CTG, não vão ao rodeio, mas querem mostrar que amam o estado.

Gerti acredita que "[...] as coisas vão sendo incorporadas, inseridas na evolução, no andar das coisas, através dos tempos, dos comportamentos das pessoas, $e$ tudo isso, vai passando a fazer parte da nossa cultura".

Foi comentado também por alguns entrevistados que às vezes as pessoas possuem o desejo de demonstrar seus sentimentos e emoções, estes estariam ligados à moda de uma forma geral, ou seja, ela é uma forma de expressão, o que corrobora com a teoria apresentada anteriormente por Lipovetsky (2009) em relação à efemeridade da moda. A moda nada mais é do que uma forma de expressão de culturas e das identidades dos indivíduos.

Luis fala sobre o mercado que se criou em torno disso, as novas modas estimulam o consumo e a demonstração da relação com a cultura. E afirma que a moda contemporânea "faz parte desta nova identidade cultural do RS."

Gerti diz que a cultura não depende do comércio, e sim o comércio da cultura, é uma troca, pois o comércio também pode estimular a disseminação da cultura. As pessoas continuam gostando e através do consumo elas podem demonstrar isso. Destacou também o grande potencial deste mercado. Porém apenas os entrevistados que moram em cidades maiores tais como Alegrete, Porto Alegre e Santa Maria possuem maior acesso a este tipo de moda. Demais entrevistados, que residem no Vale do Taquari, têm dificuldades de encontrar este tipo de roupa. As mais simples como camisetas e bombachas é mais comum, porém roupas mais elaboradas, modernas e os acessórios contemporâneos já é mais complicado, apenas pela internet em sites de lojas especializadas.

\subsubsection{Conflitos: Tradicionalismo gaúcho $\mathrm{x}$ Moda contemporânea gaúcha}

Caroline afirma que gosta de utilizar algumas roupas mais modernas com referências às tradições gaúchas, mas em ambientes e em momentos em que não está em locais como os CTG's, para evitar conflitos e críticas, já que sabe que isso não seria bem visto.

Gerti também fala sobre o respeito que se deve ter com a cultura e com as pessoas que dela participam e "pregam" os seus costumes e regras. Jéferson reforça "nós precisamos ser maleáveis e respeitar essas diferenças". Mas conforme alguns entrevistados a aceitação destas mudanças são bem difíceis.

Os entrevistados mais liberais em relação ao assunto indicam que quem gosta da cultura não deveria ter motivos para não gostar destas roupas mais modernas, pois elas continuam tentando preservar a cultura, estimulando e instigando as pessoas.

A moda contemporânea com referências à cultura gaúcha demonstra estar sendo cada vez mais incorporada por consumidores urbanos que buscam algum tipo de referência com a cultura gaúcha. Mas ao mesmo tempo, parece 
esbarrar no preconceito e na ideia de que esta nova forma de expressão pode prejudicar a preservação da cultura tradicionalista. Porém esta é apenas mais uma das possibilidades que o indivíduo tem para demonstrar o seu sentimento de pertencimento à cultura, sem desrespeitar os demais.

\subsection{Pertencimento de cultura}

O consumo de bens é apontado por Canclini (2006) como sendo um efeito da globalização e da hibridação (mistura de culturas). E isso desperta nos indivíduos o sentimento de pertencimento, de demonstração das origens da pessoa. E a moda é uma forma de realizar esta expressão do sentimento de pertencimento a uma cultura, no caso apresentado neste trabalho, a manifestação do pertencimento gaúcho é estudada através da moda contemporânea gaúcha.

Gerti afirma que o povo gaúcho gosta de demonstrar a sua cultura e tem muito orgulho dela de forma geral. As manifestações de pertencimento a uma cultura estão nos pequenos gestos como comentado por Bruna, em tomar chimarrão com a família, fazer o churrasco no domingo, compartilhar bons momentos, ir a um CTG, cantar as músicas daqui. Mas além destas formas também é possível utilizar-se das roupas como forma de expressão.

Paulo argumenta que as manifestações de pertencimento estão relacionadas com a identidade das pessoas, pois desejam participar e pertencer a grupos sociais e culturais. Segundo ele, para isso, a primeira coisa que é modificada pelo indivíduo é a sua forma de vestir-se, caso esta não estiver de acordo com o que é apresentado pelo grupo ao qual deseja se inserir.

Gerti acrescenta à discussão dizendo que as pessoas podem e devem se vestir como elas se sentem à vontade, como elas quiserem para se identificarem com os grupos aos quais elas pertencem ou desejam pertencer. Reitera que a vestimenta tem o poder de expressão, e acaba se tornando uma forma de comunicação implícita.

Caroline afirma que as discussões relativas à modernidade, as novas roupas com referências à cultura gaúcha facilitam para que as pessoas se identifiquem com as tradições e gostem dela, admirem, pois, para gostar da cultura não seria necessário pilchar-se (vestir-se de gaúcho). Diz também que a questão visual é muito importante para as realizações de demonstrações, estando vestida tradicionalmente ou com roupas mais contemporâneas com referências à cultura.

Para Marisa "A moda e a cultura estão juntas para demostrar esta questão do pertencimento". Ou seja, ela pode ser usada como forma de expressão do pertencimento. Esta comunicação acontece geralmente de forma implícita, fazendo parte do nosso dia a dia. Através de itens simbólicos ligados à cultura acabam sendo estampados, literalmente e/ou referenciados nas peças de roupas. 
Portanto, a moda contemporânea com referências à cultura gaúcha acaba sendo utilizada inclusive por pessoas que não estão necessariamente ligadas ao Movimento Tradicionalista, sendo consumida como um meio de demonstração do pertencimento destas pessoas e também das que são tradicionalistas, vinculando-as. E assim elas expressam através das vestimentas o sentimento de pertencimento do usuário das peças. Esta nova moda gaúcha vem sendo construída de forma a agregar à cultura e com o intuito de também auxiliar no processo de preservação da cultura gaúcha. Pode-se dizer também que os objetos que fazem parte do cotidiano das pessoas também auxiliam neste processo de demonstração.

O sentimento de pertencer a algum lugar, a alguma cultura vai muito além do uso de roupas e consumo de bens e serviços. Mas é importante entender que através deles também é possível realizar a demonstração deste pertencimento, e isso faz parte do dia a dia das pessoas, acaba-se praticando isso sem muitas vezes perceber, é algo involuntário, e a utilização de roupas também faz parte deste processo de manifestações de sentimentos e opiniões.

\section{CONSIDERAÇÕES FINAIS}

Este trabalho tem como objetivo analisar como o sentimento de pertencimento do povo gaúcho é mediado por objetos simbólicos ligados à moda contemporânea, para assim entender como os gaúchos demonstram a sua cultura e o seu pertencimento a ela por meio das suas roupas.

O hibridismo cultural faz com que as pessoas desejem demonstrar o seu sentimento de pertencimento a algum lugar, a alguma cultura Fearherstone (1995); e o consumo de bens e objetos simbólicos auxilia neste processo (CANCLINI, 1997). O consumo deixa de ser considerado apenas de forma econômica, mas sim social. Sendo assim, o consumo ocorre também para expressar o sentimento de pertencimento à cultura gaúcha. E para isso, as pessoas se utilizam de bens tanto materiais como imateriais.

Para Canclini (2006) o ato de consumir, comprar e principalmente o acesso ao consumo de cultura transforma os indivíduos em cidadãos. Os objetos tradicionais gaúchos citados, além de estimular o consumo e referenciar o povo as suas tradições, ainda os torna cidadãos devido ao acesso à cultura.

A relação da cultura com a moda contemporânea ainda é pouco percebida pelas pessoas entrevistadas. Através das entrevistas aplicadas é possível dizer que parte destas pessoas compreende que a demonstração da identidade cultural gaúcha e o sentimento de pertencimento são demonstrados de forma mais forte, clara e conclusiva quando as pessoas estiverem vestidas de forma tradicional, ou seja, pilchadas com roupas ditas tradicionalistas, conforme o regulamento pregado pelo MTG.

Outras pessoas, sem um comprometimento direto com o MTG, entendem que através da roupa contemporânea também é possível demonstrar 
o sentimento de pertencimento. Talvez não de forma tão clara e objetiva, mas pode-se expressar a identidade cultural desta forma. É importante destacar que a moda, o jeito com que nos vestimos é uma forma de expressão, conforme Bergamo (1998). Noronha e Schemes (2013) afirmam que a moda é uma forma de manifestação cultural, ou seja, tanto utilizando uma roupa típica gaúcha (pilcha), como uma roupa mais moderna com referências à cultura gaúcha, o indivíduo que estiver utilizando-a estará manifestando o seu pertencimento à cultura gaúcha.

Observa-se assim que, dentre os participantes da pesquisa, existem dois grupos. Um é composto por pessoas tradicionalistas, que não aprovam a moda contemporânea como forma de expressão e demonstração da cultura gaúcha. Estas em sua maioria entendem que esse tipo de atitude prejudica o desenvolvimento e preservação da cultura. Já o segundo grupo engloba as pessoas que pensam que isso apenas veio para agregar e até mesmo estimular as pessoas a se aproximarem da cultura.

Os objetos simbólicos ligados à moda são as próprias roupas típicas, que se tornam referências para o design das novas roupas. E também os itens como chimarrão, churrasco, cavalo e até mesmo expressões típicas acabam sendo representadas em estampas nas peças de roupas, fazendo assim também demonstrações de apreciação à cultura.

De fato, o sentimento de pertencimento à cultura se torna o principal fator que estimula e instiga as pessoas a procurarem objetos que demonstrem este envolvimento, algumas desejam fazer esta demonstração e outras não, são mais discretas. Porém, de forma geral, mesmo os entrevistados não ligados diretamente ao tradicionalismo gaúcho também manifestaram interesse em expressar o seu afeto à cultura como um todo. Para esta demonstração a moda acaba sendo mais democrática. Ou seja, as roupas mais modernas com referências à cultura gaúcha podem agradar tanto as pessoas mais tradicionalistas como as que não fazem parte deste meio, mas são gaúchas e apreciam a cultura de forma geral.

Sendo assim, é possível dizer que a moda pode e é utilizada como forma de expressão de identidade cultural e do sentimento de pertencimento dos indivíduos. Os gaúchos ainda estão começando a "descobrir" este nicho de mercado que é um pouco recente em relação à moda contemporânea com referências à cultura. Mas sem dúvidas irá crescer cada vez mais, auxiliando assim as pessoas no processo de demonstração do sentimento de pertencimento através do uso de roupas modernas que tenham referências à cultura gaúcha $\mathrm{e}$ que podem ser utilizadas no dia a dia das pessoas, não sendo mais necessário pilchar-se para demonstrar o envolvimento com a cultura gaúcha através de vestimentas.

Esta nova forma de demonstração é válida para todas as pessoas que apreciam a cultura, sendo envolvidas no meio ou não. A moda contemporânea vem apenas para agregar novos conceitos à cultura gaúcha, inclusive com 
referências ao que já existe e é cultuado. Ou seja, não há intenção de terminar com o tradicionalismo, mas na verdade é um senso de atualização que também faz parte do mundo hipermoderno (LIPOVETSKY, 2009), assim, utilizando-se de tudo isso como uma forma de demonstração do pertencimento à cultura.

A pesquisa teve o objetivo de verificar e analisar como acontece o processo de demonstração do sentimento de pertencimento à cultura gaúcha através do uso da moda contemporânea. São muitas as abordagens, temáticas e fatores que influenciaram cada uma das respostas dos participantes da pesquisa. E isso também se deve à formação da identidade de cada um deles, a proximidade ou não deles com a cultura, o nível de importância que cada um deu para o assunto, a própria visão de alguns em relação ao tema da pesquisa no momento em que foi apresentado. Ou seja, parte das limitações do estudo se deve justamente às diferentes percepções das pessoas, o que ao mesmo tempo o enriquece devido ao grande volume de dados que foram gerados a partir das entrevistas. Como cada indivíduo possui uma identidade diferente, que foi constituída de formas diferentes (HALL, 2006), é comum que as pessoas não concordem sempre umas com as outras.

O estudo tratou em específico da relação entre a moda e o pertencimento à cultura gaúcha, mas ainda existem outras áreas dentro do mesmo tema a serem observadas e aprofundadas, visto que a construção da identidade do povo gaúcho poderia ser mais explorada, bem como os fatores e objetos simbólicos que estimulam o sentimento de pertencimento, que influenciam na moda assim como demonstrações realizadas de outras formas.

As peças de roupas e acessórios contemporâneos citados ao decorrer do trabalho tornam-se objetos simbólicos da cultura gaúcha, e estes auxiliam no processo de demonstração do sentimento de pertencimento do indivíduo pós-moderno, que faz parte de uma cultura híbrida, que se utiliza também do consumo de bens e serviços para através deles realizar a sua demonstração de pertencimento à cultura gaúcha. Sendo assim, este estudo é importante para que se possa compreender como a cultura influencia no comportamento do consumidor.

\section{REFERÊNCIAS}

ANDRADE, Maria Margarida de. Introdução à metodologia do trabalho científico: elaboração de trabalhos na graduação. 6. ed. São Paulo: Atlas, 2003.

ARNOULD, Eric J.; THOMPSON, Craig J. Consumer Theory (CCT): twenty years of research. 2005. Disponível em: <http://www.jstor.org/stable/10.1086/426626>. Acesso em: 01 ago. 2016.

BARDIN, Laurence. Análise de conteúdo. Tradução de Luís Antero Reto e Augusto Pinheiro. Lisboa: Edições 70 LDA, 2006. 
BAUMAN, Zygmunt. Modernidade Líquida. Tradução de Plínio Dentizien. Rio de Janeiro: Zahar, 2001.

BERGAMO, Alexandre. O campo da moda. Texto digital. 1998.

Disponível em: <http:/ / www.scielo.br/scielo.php?script=sci_

arttext\&pid=S0034-77011998000200005> . Acesso em: 16 set. 2016.

CANCLINI, Néstor García. Culturas Híbridas y estrategias comunicacionales:

Estudios sobre las culturas contemporaneas. Read de Revistas Científicas de América Latina y el Caribe, España y Portugal. Colima, México, v. 3, n. 5, jun. 1997.

Consumidores e Cidadãos. Tradução de Maurício Santana Dias. Rio de Janeiro: Editora UFRJ, 2006.

A globalização imaginada. Tradução de Sérgio Molina. 1. reimpr. São Paulo: Iluminuras, 2007.

COBRA, Marcos. Marketing e moda. São Paulo: Editora Senac São Paulo; Cobra Editora \& Marketing, 2007.

COSTA, António Firmino da. Identidades culturais urbanas em época de globalização. Revista Brasileira de Ciências Sociais, São Paulo, v. 17, n. 48, 2002. Disponível em: <http:/ /www.scielo.br/pdf/rbcsoc/v17n48/13947>. Acesso em: 7 set. 2016.

CRESWELL, John W. Projeto de pesquisa: métodos qualitativo, quantitativo e misto. Tradução de Luciana de Oliveira da Rocha. 2. ed. Porto Alegre: Artmed, 2007.

DESBESSELL, Carolina Quadros. A influência do estilo do consumidor contemporâneo na indumentária gauchesca feminina. 1999. Disponível em: <http:/ / www.paginadogaucho.com.br/indu/influ.htm>. Acesso em: 20 set. 2016.

DOUGLAS, Mary; ISHERWOOD, Baron. O mundo dos bens: para uma antropóloga do consumo. Tradução de Plínio Dentzien. Rio de Janeiro: Editora UFRJ, 2004.

GOBBI, Maria Cristina. A mídia das comunidades periféricas. In: Folkcomunicação: a mídia dos excluídos. Cadernos da comunicação 17, Rio de Janeiro: Secretaria Especial de Comunicação Social RJ, p. 21-28, 2007.

HALL, Stuart. Da diáspora identidades e mediações culturais. Tradução de Adelaine La Guardia Resende [et al.]. SOVIK, Liv. (Org.). Belo Horizonte: Editora UFMG; Brasília: Representação da UNESCO no Brasil, 2003.

A identidade cultural na pós-modernidade. 11. ed. Tradução de Tomas Tadeu da Silva e Guacira Lopes Louro. Rio de Janeiro: DP\&A, 2006.

LIPOVETSKY, Gilles. Os tempos hipermodernos. 32. ed. Tradução de Mário Vilela. São Paulo: Editora Barcarolla, 2004. 
O império do efêmero: a moda e seu destino nas sociedades modernas.

Tradução de Maria Lúcia Machado. São Paulo: Companhia das Letras, 2009.

MOVIMENTO TRADICIONALISTA GAÚCHO - MTG. Diretrizes para a pilcha gaúcha. jul. 2014. Disponível em: <http:/ / www.mtg.org.br/public/libs/kcfinder/ upload/files/DIRETRIZES\%20PARA \%20A\%20PILCHA \%20GA\%C3\%9ACHA $\% 20$ -\%202015.pdf>. Acesso em: 20 set. 2016.

NORONHA, Renata Fratton; SCHEMES, Cláudia. A identidade regional celebrada no vestir: a moda que vem do sul e as reportagens fotográficas. São Paulo: Unesp, v. 9, n. 2, p. 152-177, jul./dez. 2013.

OLIVEIRA, Talita Souza de. Moda: um fator social. 2013. Disponível em: <http:/ / www.teses.usp.br/teses/disponiveis/100/100133/tde-13052013-161455/pt-br.php>. Acesso em: 18 set. 2016.

OLIVEN, Ruben George. A parte e o todo: a diversidade cultural no Brasil-nação. São Paulo: Vozes, 1993.

PESAVENTO, Sandra. A invenção da sociedade gaúcha. Ensaios FEE, [S.1.], n. 2, p. 383-396, 1993.

RIO GRANDE DO SUL (Estado). Lei 8.813, de 10 janeiro de 1989. Dispõe sobre a indumentária denominada pilcha gaúcha. Disponível em: <http:/ / www.al.rs.gov.br/legis/M010/M0100099.ASP?Hid_Tipo=TEXTO\&Hid_ TodasNormas=19552\&hTexto=\&Hid_IDNorma=19552>. Acesso em: 20 set. 2016.

SOLOMON, Michael R. O comportamento do consumidor: comprando, possuindo e sendo. Tradução de Luiz Cláudio de Queiroz Faria. 9. ed. Porto Alegre: Bookman, 2011.

SVENDSEN, Lars. Fashion: a Philosophy. London: Reaktion Books, 2006.

VERGARA, Sylvia Constant. Projetos e relatórios de pesquisa em administração. São Paulo: Atlas, 2000.

WOODWARD, Kathryn. Identidade e diferença: uma introdução teórica e conceitual. In: SILVA, Tomaz Tadeu da (Org.). Identidade e Diferença: a perspectiva dos estudos culturais. Petrópolis, RJ: Vozes, 2000. p. 7 - 72. 